Figure S1

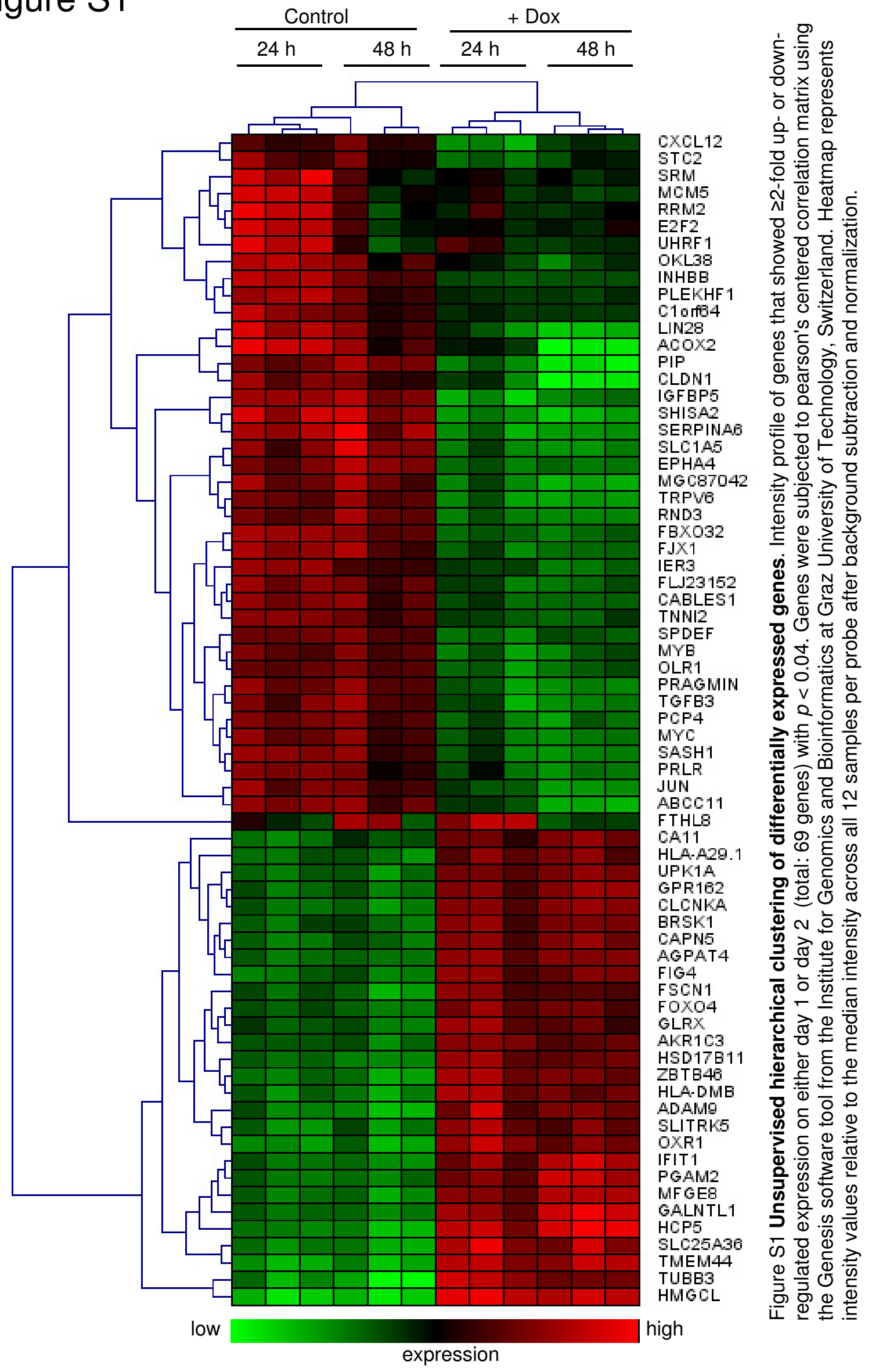




\section{Figure S2}

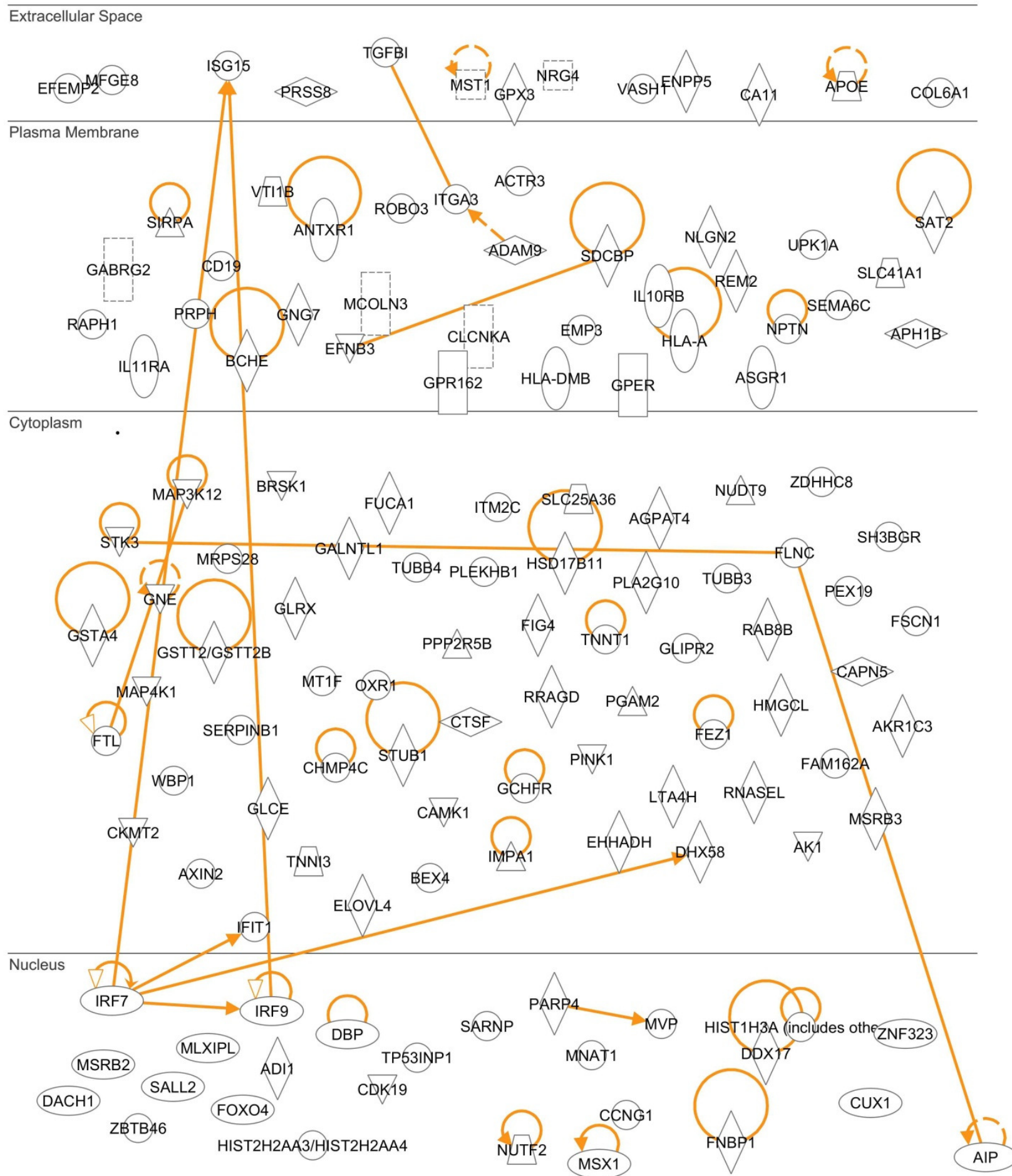

Figure S2 Pathway analysis of genes up-regulated by PIP knockdown. 273 genes up-regulated by $\geq 1.5$-fold one day after PIP knockdown were subjected to the pathway analysis tool from Ingenuity Systems (IPA ${ }^{\mathrm{TM}}$ ). Connections are shown among 132 genes for which matched entries were found. Each connection indicates at least one direct relationship found in the literature. 


\section{Figure S3}
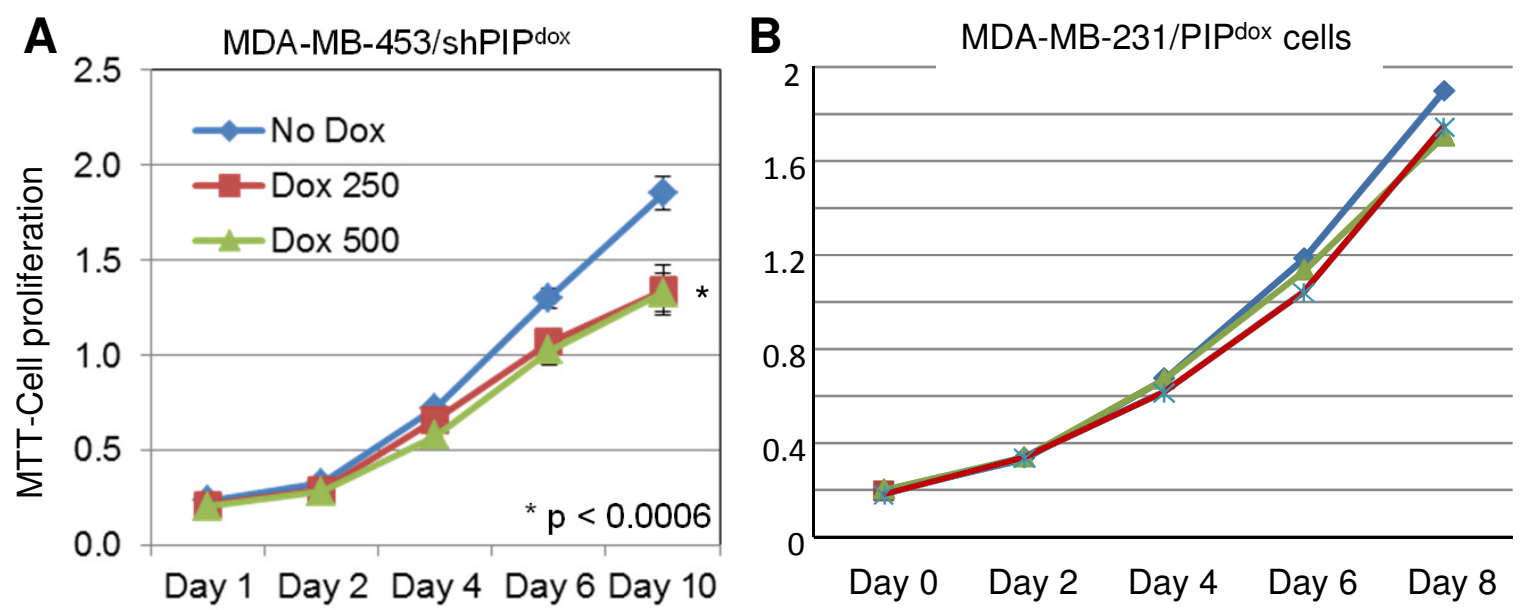

Figure S3 PIP is required for the proliferation of ER-negative MDA-MB-453 cells. Expression of PIP was either knocked-down in PIP-positive MDA-MB-453 cells (A) or induced in PIP-negative MDA-MB-231 cells (B) using lentiviral particles encoding shPIPdox or PIPdox, respectively. Cell proliferation was assessed using MTT assays at the indicated time points. Cells cultures were treated with either 250 $\mathrm{ng} / \mathrm{ml}$ or $500 \mathrm{ng} / \mathrm{ml}$ of Dox, and an equal volume of distilled water was used as vehicle control. 
Figure S4
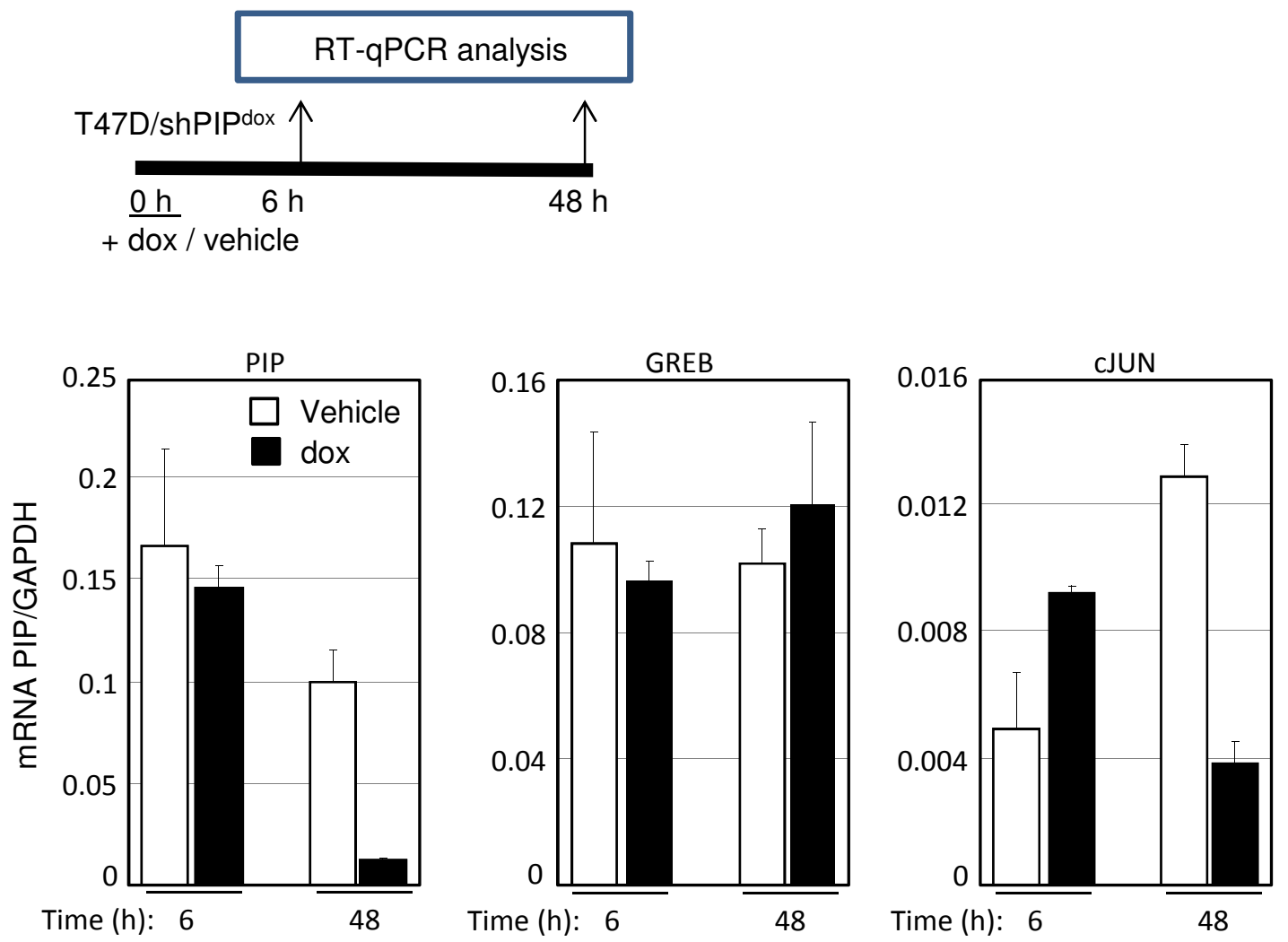

Figure S4 RT-qPCR analysis of PIP and its target cJUN after PIP knockdown. RNA was extracted after $6 \mathrm{~h}$ and $48 \mathrm{~h}$ treatment of T47D/shPIPdox cells with either dox $(250 \mathrm{ng} / \mathrm{ml})$ or vehicle as schematically illustrated in the upper panel. Expression levels of PIP, GREB, and cJUN were measured relative to GAPDH as control (lower panel). The result demonstrate that Dox-induced shPIP expression decreased PIP and increased cJUN mRNA levels at the 48, but not at the 6-hour time point. RTqPCR analysis of GREB is presented as negative control. 